\title{
Vacuum-Assisted Breast Biopsy System: No Innovation Without Evaluation
}

\author{
Sherif Monib $^{1}$, Soumitra Mukerji ${ }^{2}$, Sonia Narula ${ }^{2}$ \\ 1. Breast Surgery, West Hertfordshire Hospitals NHS Trust, St Albans, GBR 2. Radiology, West Hertfordshire Hospitals \\ NHS Trust, St Albans, GBR
}

Corresponding author: Sherif Monib, sherif.monib@nhs.net

\section{Abstract \\ Background}

Vacuum-assisted breast biopsy (VABB) has recently been gaining more popularity as a modality to reach the final diagnosis, especially in indeterminate breast lesions, resulting in a decreased number of surgical interventions and unnecessary follow-ups.

\section{Objective}

While our primary aim was to look into the outcomes of the VABB technique, our secondary aim was to assess the impact of the method on changes in patients' management.

\section{Patients and methods}

This study was a retrospective database analysis of vacuum-assisted biopsies (VABs) carried out at our breast unit during the period between January 2011 and January 2018. All our cases were image-guided; the caliber of vacuum-assisted needles used was 8 gauge $(\mathrm{G})$ and $11 \mathrm{G}$. Patient demographics, lesion characteristics, and outcomes were retrieved from patients' notes and the hospital database.

\section{Results}

A total of 122 female patients were included in the analysis, out of whom $41.8 \%$ (51 patients) were screendetected, and $58.1 \%$ (71 patients) were symptomatic presentations. The mean lesion size on imaging was $14.8 \mathrm{~mm}$ (SD: 12.6); 50\% (61 patients) had stereotactic vacuum-assisted breast biopsy (SVAB), and 50\% (61 patients) had ultrasound-guided vacuum-assisted breast biopsy (US-VAB). Post-procedure histology was upgraded in $19.6 \%$ (24 patients), downgraded in $18.8 \%$ (23 patients), and remained unchanged in $61.4 \%$ (75 patients).

\section{Conclusion}

Review began 01/03/2021 Review ended 01/07/2021 Published 01/12/2021

\section{(c) Copyright 2021}

Monib et al. This is an open access article distributed under the terms of the Creative Commons Attribution License CC-BY 4.0., which permits unrestricted use, distribution, and reproduction in any medium, provided the original author and source are credited.
VABB is a safe and efficient procedure for the diagnosis and management of indeterminate and suspicious breast lesions. It provides an adequate amount of tissue, which can help in upgrading or downgrading histopathologically diagnosed patients, thereby decreasing the need for surgery.

\author{
Categories: Radiology, Oncology \\ Keywords: breast cancer- minimally invasive diagnosis- vacuum-assisted biopsy-vacuum assisted excision- \\ stereotactic vacuum - calcifications
}

\section{Introduction}

In 1989, Parker started performing percutaneous biopsies, using a core needle and an automatic deployment device. In 1995, Mark Retchard, a medical device engineer, and Fred Burbank, a radiologist, developed the technique of vacuum-assisted breast biopsy (VABB) to overcome the shortcomings of core biopsies and improve the accuracy of biopsies of microcalcification (MCC) in adipose breast tissue by using an automatic biopsy gun $[1,2]$.

Soon, VABB was proven to be an excellent alternative to surgical biopsy, and it came to be associated with high diagnostic accuracy and low patient discomfort [3]. Given that larger tissue samples are obtained by $\mathrm{VABB}$, and the histological diagnosis is more accurate, the role of the vacuum-assisted biopsy (VAB) was extended to therapeutic procedures [4].

Advantages of VABB over standard core biopsy include the fact that it reduces sampling errors, imaginghistological discordance, as well as re-biopsy rates. Indications of VABB include 1) clarification of B3 lesions [atypical ductal hyperplasia (ADH), atypical lobular hyperplasia (ALH), lobular carcinoma in situ (LCIS), papillary lesions, radial scar, flat epithelial atypia]; 2) excision of benign lesions with curative intent; 3) re- 


\section{Cureus}

biopsy of discordant cases lacking correlation of suspected diagnosis and histology; 4) MCC following B1/B3/B4 result on core biopsy; and 5) diagnostic excision of papillary lesions and radial scars diagnosed on core biopsy.

In this study, we aimed to look into the outcomes of the VABB technique, focusing on safety as well as the impact of the technique on patient management.

\section{Materials And Methods}

\section{Study setting}

This study was conducted at the St Albans breast unit, West Hertfordshire Hospitals NHS Trust, UK.

\section{Ethical considerations}

The Ethical Committee approval was not required as this was a retrospective study.

\section{Study design}

We conducted a retrospective database analysis of symptomatic as well as screen-detected patients who had VABs or excisions in our breast unit during the period from January 2011 till January 2018. All patients had triple assessments including clinical breast examination followed by a digital mammogram and/or breast ultrasound scan, followed by an initial $14 \mathrm{G}$ core biopsy. MRI was carried out for a select group of patients.

The results of triple assessments were discussed among our multidisciplinary team (MDT), and the decision to proceed with VABB was in line with the MDT in all cases. Patient demographics, lesion characteristics, and patient outcomes were retrieved from patients' notes, the Clinical Record Interactive Search

(CRIS) system, and the picture archiving and communication system (PACS). All patients were seen in the clinic one week after the procedure for clinical examination and to discuss histological findings and management plans.

\section{Results}

We included 122 females patients in the analysis. Among them, 41.8\% (51 patients) were screen-detected and $58.1 \%$ (71 patients) were symptomatic presentations; $52.4 \%$ (64 patients) had right-side lesions, while $47.5 \%$ (58 patients) had left-side lesions. Mammographic findings revealed that $41.8 \%$ (51 patients) had MCC, 9\% (11 patients) had mammographic distortion, and 46.7\% (57 patients) had mass lesions; the mean lesion size on imaging was 14.8 mm (SD: 12.6) (Figure 1, Figure 2, Figure 3, Figure 4, Figure 5).

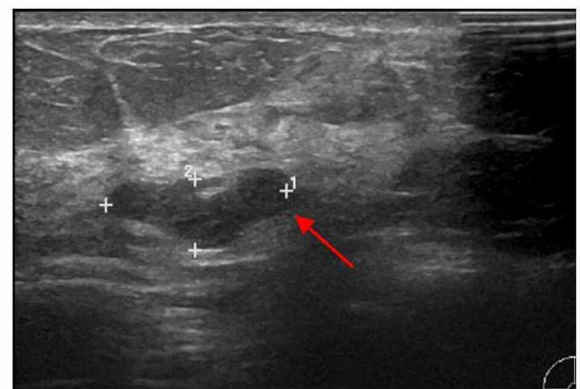

A : Pre vacuum

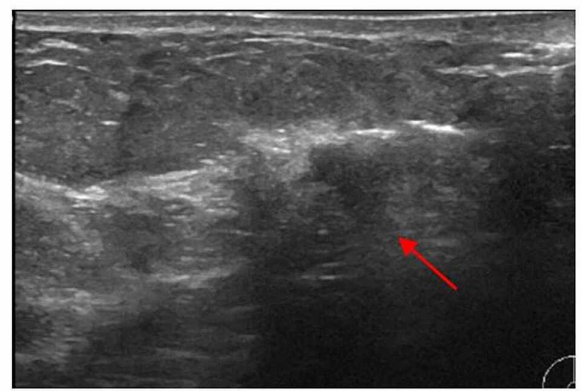

B: Post vacuum

FIGURE 1: Left breast ultrasound scan of a 9 o'clock-located 16-mm fibroadenoma with LCIS in a 60-year-old female patient

LCIS: lobular carcinoma in situ 


\section{Cureus}

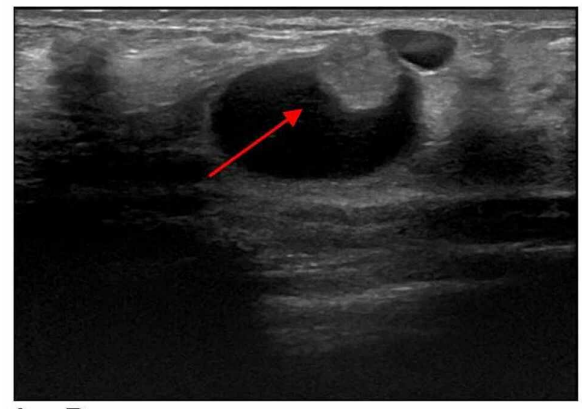

A : Pre vacuum

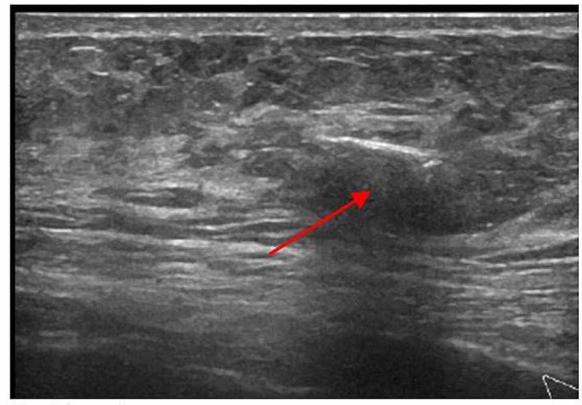

B: Post vacuum

FIGURE 2: Right breast ultrasound scan of a 10 o'clock-located 18-mm intracystic papilloma in a 44-year-old female patient

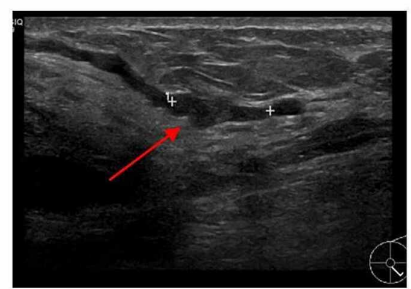

A : Pre vacuum

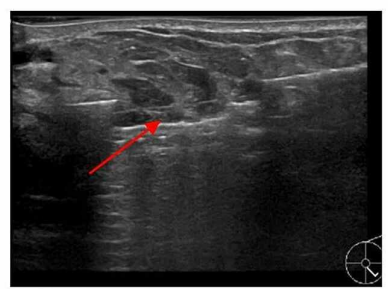

B:During $V A B$

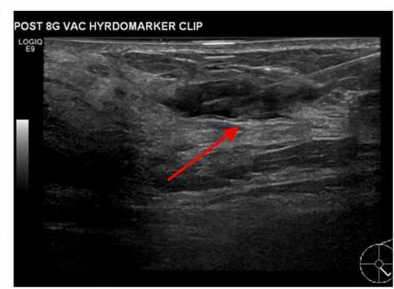

C: Post vacuum

FIGURE 3: Left breast, 5 o'clock, 13-mm intraduct papilloma in a 43year-old female patient

VAB: vacuum-assisted biopsy

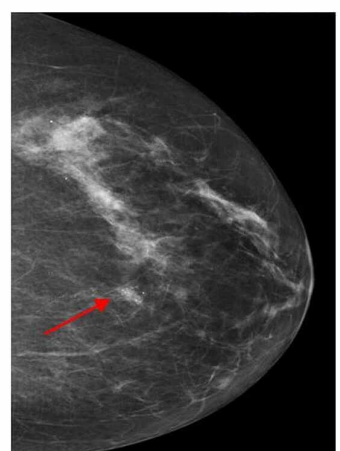

A : Pre vacuum CC

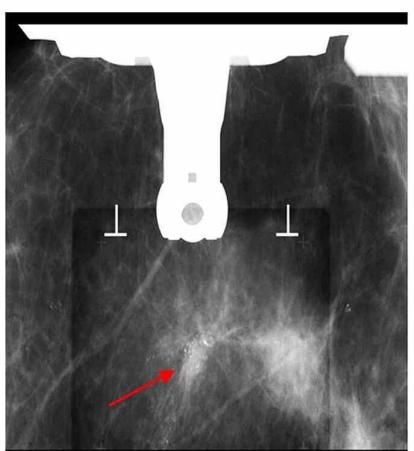

$B$ : Stereo guided $V A B$

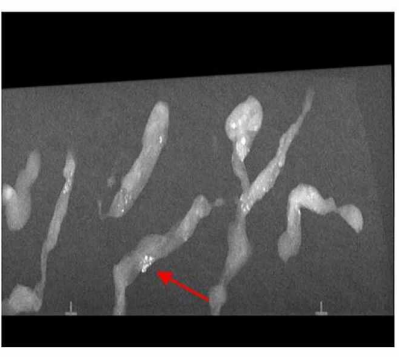

C: Specimen MCC

FIGURE 4: Left breast, 12 o'clock, 34-mm DCIS in a 59-year-old female patient

DCIS: ductal carcinoma in situ; CC: craniocaudal; VAB: vacuum-assisted biopsy; MCC: microcalcification 


\section{Cureus}

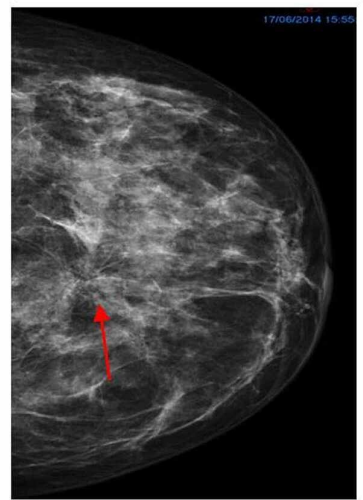

A : Pre vacuum $\mathrm{CC}$ view

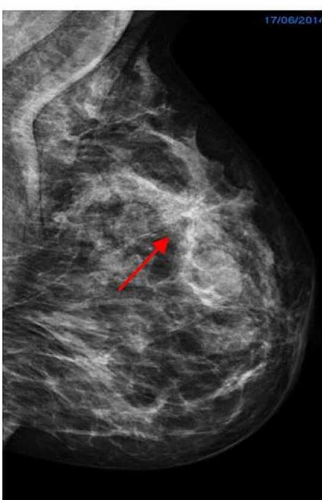

B: Pre vacuum MLO view

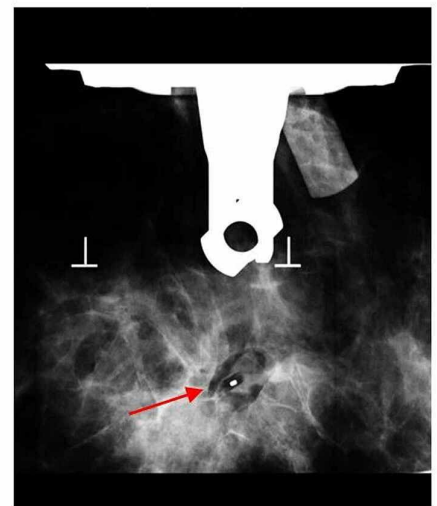

C: Stereo guided VAB

FIGURE 5: Left breast, 12 o'clock, 25-mm radial scar in a 55-year-old female patient

CC: craniocaudal; MLO: mediolateral oblique; VAB: vacuum-assisted biopsy

All procedures were image-guided; 50\% (61 patients) underwent stereotactic vacuum-assisted breast biopsy (SVAB), and 50\% (61 patients) had ultrasound-guided vacuum-assisted breast biopsy (US-VAB). Vacuumassisted excisions (VAEs) using an $8 \mathrm{G}$ needle were carried out for 68\% (83 patients), and VABs using an $11 \mathrm{G}$ needle were carried out for $31.9 \%$ ( 39 patients) of the cohort. Our overall immediate complications rate was $3.2 \% ; 2.4 \%$ (three patients) developed a hematoma, which was treated conservatively, and $0.8 \%$ (one patient) had skin breakdown, which was also treated conservatively.

\section{Histological findings}

Pre-procedure histology grading was B1 in 4.9\% (six patients), B2 in 6.5\% (eight patients), B3 in $81.1 \%$ (99 patients), B4 in $0.8 \%$ (one patient), B5a in $2.4 \%$ (three patients), and B5b in $4 \%$ (five patients) (Table 1).

\begin{tabular}{|l|l|}
\hline Histological grading & $\%$ (number of patients) \\
\hline B1 & $4.9 \%$ (6 patients) \\
B2 & $6.5 \%$ (8 patients) \\
B3 & $81.1 \%$ (99 patients) \\
B4 & $0.8 \%$ (1 patient) \\
B5a, B5b & $2.4 \%$ ( 3 patients), $4 \%$ (5 patients)
\end{tabular}

TABLE 1: Pre-procedure histological grading

Post-procedure histology was upgraded from B1, B2, B3, and B4 to B5a or B5b in 18\% (22 patients); it was downgraded from B3 to B2 in 18.8\% (23 patients), and was unchanged in 63.1\% (77 patients) (Table 2, Table 3).

Histological grading

Upgraded from B1, B2, and B3 to B5a or B5b

Downgraded from B3 to B2

Unchanged
$\%$ (number of patients)

$18 \%$ (22 patients)

$18.8 \%$ (23 patients)

$63.1 \%$ (77 patients)

TABLE 2: Post-procedure histological grading 


\section{Cureus}

Pre-vacuum pathology

B1: $2.4 \%$ (3 patients)

B2: $0.8 \%$ (1 patient)

B3: $13.9 \%$ (17 patients)

B4: $0.8 \%$ (1 patient)
Post-vacuum pathology

B3: $1.6 \%$ (2 patients), B5b: 0.8\% (1 patient)

B3: $0.8 \%$ (1 patient)

B5a: $9 \%$ (11 patients), B5b: 4.9\% (6 patients)

B5b: $0.8 \%$ (1 patient)

TABLE 3: The breakdown of upgraded pathology

\section{Impact of VAB on management}

Of note, 31.1\% (38 patients) were discharged; 9\% (11 patients) required a follow-up mammogram or US scan with or without re-biopsy, while $24.5 \%$ (30 patients) required five-year surveillance mammograms, and $28.6 \%$ (35 patients) required definitive surgical treatment in the form of wide local excision or a mastectomy.

\section{Discussion}

Indeterminate (B3) breast lesions represent a heterogeneous group of abnormalities; its incidence is $5 \%$ in screen-detected patients, which is slightly higher than that in symptomatic patients [5]. While repeat biopsy does not always provide a definitive diagnosis, VABB not only provides enough tissue for assessment but also can provide definitive treatment at the same time.

There are no strict guidelines regarding the maximum size of lesions that can be safely excised using VABB; however, excisions are usually limited to lesions under $30 \mathrm{~mm}$ due to time constraints and reasons related to patient comfort. In our cohort, the mean lesion size was $14.8 \mathrm{~mm}$ (SD: 12.6). Park et al. have concluded in their analysis that it is safe to use VABB to resect lesions of $<3 \mathrm{~cm}[6]$.

VABs are always carried out under image-guidance; selection of the best modality is based on the modality's ability to show the index lesion and where the lesion is easily accessible for the procedure [7]. SVAB was introduced by Burbank and Parker in 1996 as a diagnostic tool to evaluate suspicious lesions visible on mammography [2]. It was found to be accurate as a method of open surgical biopsy with lower complication rates; also, mammographic changes after surgical biopsies, such as architectural distortion, parenchyma scar, calcifications, fat necrosis, and asymmetric glandular tissue defects have been well described and may mimic the mammographic signs of malignancy [8]. US-VAB was first performed by Zannis et al. in 1998 [2]. It is considered a good alternative in cases with mammographically occult breast lesions and for excision of benign lesions, such as fibroadenoma, papilloma, and radial scars [7]. MRI-guided VABB is also an accurate method for diagnosing breast lesions not seen on mammogram or US scan [9]. Recently, tomosynthesisguided VABB (TVAB) has also been proven to be able to biopsy small architectural distortions and MCC with high accuracy [10]. Of note, $53.6 \%$ of our cases were SVABs, while $46.3 \%$ were US-VABs.

VABB needles come in $8 \mathrm{G}, 11 \mathrm{G}$, or $14 \mathrm{G}$ diameters; the $14 \mathrm{G}$ needle is the least invasive, and it can collect 40 $\mathrm{mg}$ of tissue per insertion. The $11 \mathrm{G}$ needle can collect $100 \mathrm{mg}$ of tissue, and hence it can be used to completely resect lesions of $<1 \mathrm{~cm}$. The $8 \mathrm{G}$ needle can collect $250 \mathrm{mg}$ of tissue, and hence it is capable of resecting palpable breast lesions smaller than $3 \mathrm{~cm}$ [2]. Other needles used are the $13 \mathrm{G}$, 9G, and 7G monobloc excision needles [11]. In our cohort, we used $8 \mathrm{G}$ for VAEs and $11 \mathrm{G}$ for VABs. den Dekker et al. found that six $9 \mathrm{G}$ VAB specimens are enough to reach a final histopathological diagnosis in $95 \%$ of cases [12]. In our practice, we always aim to take 12 specimens for VAB and between 12-20 specimens for VAE to achieve complete excision.

In our experience, for diagnostic VAEs, adequate sampling can be ensured by undertaking lesion excision in two steps: inner ring for the lesion and outer ring (with clock-face circumferential sampling) for lesion margins, to emulate surgical excision. This gives the pathologist enough tissue for the analysis of the lesion as well as its margins.

Following VAB for MCC/ductal carcinoma in situ (DCIS), around 10\% of patients are usually found to have invasive diseases [13]; this upgrade is essential for surgical planning as not only patients with invasive disease but also those with mass-forming DCIS will require a sentinel lymph node biopsy at the time of definitive surgery [14]. In our cohort, post-procedure histology was upgraded from B2, B3, and B4 to B5a or $\mathrm{B} 5 \mathrm{~b}$ in $18 \%$ (22 patients), downgraded from B3 to B2 in 18.8\% (23 patients), and was unchanged in $63.1 \%$ (77 patients); out of the initial $99 \mathrm{~B} 3$ lesions that were downgraded, eight patients were discharged, and six patients had planned surveillance. It is worth mentioning that by using the VABB technique, we diagnosed 19 additional cancers (15.5\%), out of which 11 (9\%) were non-invasive, and eight (6.5\%) were invasive 
cancers.

Unfortunately, VABB is not without complications; to minimize the incidence of possible complications, $\mathrm{VABB}$ is not recommended in cases with scattered MCC, lesions close to the skin, areola and nipple complex, or chest wall due to the difficulty in access and increased risk of skin dehiscence. While Park et al. reported a complication rate of $2.5 \%$ including bleeding, hematoma formation, skin injury, and dimple formation, or even pneumothorax [15], Hu et al. reported pain in $22.6 \%$, hematomas formation in $9.7 \%$, and ecchymosis in $3.2 \%$ [16]. US-VAB is associated with a slightly higher risk of bleeding when compared to SVAB, which can be attributed to the lack of breast compression during the US-guided procedure [17].

Our cohort's overall immediate complications rate was 3.2\% (4/122 patients), with $2.4 \%$ (3/122 patients) developing a hematoma, which was treated conservatively, and $0.8 \%$ (1/122 patient) with skin breakdown, which was also treated conservatively. It is worth mentioning that most of the patients who developed complications had mostly superficial lesions. Our low complication rate was due to careful procedure technique, use of a combination of local anesthetic lidocaine with adrenaline (1 in 200,000) to reduce the risk of bleeding, use of excision guidance (ultrasound versus stereotactic) to best suit the lesion position, and avoiding access close to nipple and chest wall. The close proximity to the skin can sometimes be overcome by excising from above than from below, such that the cutting edge of the device is facing the depth of breast tissue away from the skin, thereby reducing the risk of skin dehiscence. Infiltration of local anesthetic and saline can be helpful in increasing the depth between the lesion and the chest wall, thereby enabling excision of posteriorly placed lesions close to the chest wall. We also feel that excising the lesion in the inner (lesion) and outer ring (margin/periphery) enhances the specimen yield and also gives a margin excision equivalent, thus mimicking surgical excision, especially in lesions such as papillomata and radial scar.

Other possible complications include clip migration, which is seen more with superficial lesions, and high specimen number [18]. In our cohort, we did not come across significant clip migration cases. Also, inadequate sampling or missed lesions can significantly affect patient outcomes; therefore, intraprocedural, early post-procedural mammography, as well as specimen radiography are required to ensure adequate sampling $[15,19]$. As skin injury was also reported as a possible complication, Berná-Serna et al. used a simple, safe technique to prevent skin injury during VABB by inserting a spinal needle between the skin and the mass [20].

Perretta et al. found US-guided VAE to be highly successful with a complete excision rate of $93.61 \%$; they also found that circumscribed margins, regular shape, parallel orientation, and the absence of posterior features were favorable US features associated with complete excision [21]. van de Voort et al. also found VAE to be safe and effective for benign lesions of up to $50 \mathrm{~mm}$; moreover, their patients reported good cosmetic outcomes [22].

While all our patients and most cases in the literature have been females, Atallah NG has reported the first case of US-VAB for a man with breast MCC, which was found to be a case of DCIS [23]. Also, Qu et al. found VAE to be a feasible and minimally invasive approach for the treatment of gynecomastia [24]. VABB is associated with significantly lower procedural costs when compared to open surgery, without compromising on the quality of patient care [25].

\section{Limitations}

Our study has some limitations. One of them was the low number of patients, which limited the statistical powering of our study. Another limitation is the fact that we are still in the process of following up on patients.

\section{Conclusions}

$\mathrm{VABB}$ is a safe and efficient procedure for the assessment and management of indeterminate and suspicious breast lesions, which not only avoids open surgical procedures in the majority of cases but also helps to avoid histological underestimation, resulting in significant cost savings. It is generally well tolerated by patients and is especially suitable for papillary neoplasms, lobular neoplasia (LN), atypical intraductal epithelial proliferation (AIDEP), flat epithelial atypia, and radial scar excision, with an acceptable complication rate.

\section{Additional Information \\ Disclosures}

Human subjects: Consent was obtained by all participants in this study. Animal subjects: All authors have confirmed that this study did not involve animal subjects or tissue. Conflicts of interest: In compliance with the ICMJE uniform disclosure form, all authors declare the following: Payment/services info: All authors have declared that no financial support was received from any organization for the submitted work. Financial relationships: All authors have declared that they have no financial relationships at present or 
within the previous three years with any organizations that might have an interest in the submitted work. Other relationships: All authors have declared that there are no other relationships or activities that could appear to have influenced the submitted work.

\section{References}

1. Parker SH, Stavros AT, Dennis MA: Needle biopsy techniques. Radiol Clin North Am. 1995, 33:1171-86.

2. Park HL, Hong J: Vacuum-assisted breast biopsy for breast cancer. Gland Surg. 2014, 3:120-7. 10.3978/j.issn.2227-684X.2014.02.03

3. Bozzini A, Cassano E, Raciti D, Disalvatore D, Pala O, Vingiani A, Renne G: Analysis of efficacy and accuracy of 2 vacuum-assisted breast biopsy devices: Mammotome and Elite. Clin Breast Cancer. 2018, 18:e1277-82. 10.1016/j.clbc.2018.06.014

4. Iwuagwu O, Drew P: Vacuum-assisted biopsy device-diagnostic and therapeutic applications in breast surgery. Breast. 2004, 13:483-7. 10.1016/j.breast.2004.06.004

5. Hunt RJ, Steel JR, Porter GJ, Holgate CS, Watkins RM: Lesions of uncertain malignant potential (B3) on core biopsy in the NHS Breast Screening Programme: is the screening round relevant?. Ann R Coll Surg Engl. 2012, 94:108-11. 10.1308/003588412X13171221498460

6. Park HL, Kwak JY, Jung H, Lee S, Shim JY, Kim J, Lee KS: Is Mammotome excision feasible for benign breast mass bigger than $3 \mathrm{~cm}$ in greatest dimension?. J Korean Surg Soc. 2006, 70:25-9.

7. Youk JH, Kim MJ, Son EJ, Kwak JY, Kim EK: US-guided vacuum-assisted percutaneous excision for management of benign papilloma without atypia diagnosed at US-guided 14-gauge core needle biopsy. Ann Surg Oncol. 2012, 19:922-8. 10.1245/s10434-011-2033-4

8. Bruening W, Fontanarosa J, Tipton K, Treadwell JR, Launders J, Schoelles K: Systematic review: comparative effectiveness of core-needle and open surgical biopsy to diagnose breast lesions. Ann Intern Med. 2010, 152:238-46. 10.7326/0003-4819-152-1-201001050-00190

9. Spick C, Schernthaner M, Pinker K, et al.: MR-guided vacuum-assisted breast biopsy of MRI-only lesions: a single center experience. Eur Radiol. 2016, 26:3908-16. 10.1007/s00330-016-4267-9

10. Waldherr C, Berclaz G, Altermatt HJ, et al.: Tomosynthesis-guided vacuum-assisted breast biopsy: a feasibility study. Eur Radiol. 2016, 26:1582-9. 10.1007/s00330-015-4009-4

11. Tourasse C, Khasanova E, Sebag P, Beregi JP: Ultrasound-guided vacuum-assisted breast biopsy with a small-caliber device: a multicenter consecutive study of 162 biopsied lesions. Tumori. 2019, 105:312-8 10.1177/0300891618784786

12. den Dekker BM, van Diest PJ, de Waard SN, Verkooijen HM, Pijnappel RM: Stereotactic 9-gauge vacuumassisted breast biopsy, how many specimens are needed?. Eur J Radiol. 2019, 120:108665. 10.1016/i.ejrad.2019.108665

13. Jackman RJ, Burbank F, Parker SH, et al.: Stereotactic breast biopsy of nonpalpable lesions: determinants of ductal carcinoma in situ underestimation rates. Radiology. 2001, 218:497-502. 10.1148/radiology.218.2.r01fe35497

14. Esen G, Tutar B, Uras C, Calay Z, İnce Ü, Tutar O: Vacuum-assisted stereotactic breast biopsy in the diagnosis and management of suspicious microcalcifications. Diagn Interv Radiol. 2016, 22:326-33. 10.5152/dir.2015.14522

15. Park HL, Kim LS: The current role of vacuum assisted breast biopsy system in breast disease . J Breast Cancer. 2011, 14:1-7. 10.4048/jbc.2011.14.1.1

16. Hu H, Zhang M, Liu Y, Li XR, Liu G, Wang Z: Mammary hamartoma: is ultrasound-guided vacuum-assisted breast biopsy sufficient for its treatment?. Gland Surg. 2020, 9:1278-85. 10.21037/gs-20-437

17. Simon JR, Kalbhen CL, Cooper RA, Flisak ME: Accuracy and complication rates of US-guided vacuumassisted core breast biopsy: initial results. Radiology. 2000, 215:694-7. 10.1148/radiology.215.3.r00jn37694

18. Wang J, Chien N, Lee HT: Clip migration after stereotactic vacuum-assisted breast biopsy with the patient in the decubitus position. Eur Radiol. 2020, 30:6080-88. 10.1007/s00330-020-07015-0

19. Lai JT, Burrowes P, MacGregor JH: Vacuum-assisted large-core breast biopsy: complications and their incidence. Can Assoc Radiol J. 2000, 51:232-6.

20. Berná-Serna JD, Guzmán-Aroca F, Berná-Mestre JD, Hernández-Gómez D: A new method for the prevention of skin laceration during vacuum-assisted breast biopsy. Br J Radiol. 2017, 90:20160866. 10.1259/bjr.20160866

21. Perretta T, Lamacchia F, Ferrari D, et al.: Evaluation of ultrasound-guided 8-gauge vacuum-assisted excision system for the removal of US-detectable breast lesions. Anticancer Res. 2020, 40:1719-29. 10.21873/anticanres.14125

22. van de Voort EMF, Klem TMAL, Struik GM, Birnie E, Sinke RHJA, Ghandi A: Patient reported cosmetic outcome after vacuum assisted excision of benign breast lesions: a cross-sectional study. Br J Radiol. 2020, 93:20190994. 10.1259/bjr.20190994

23. Atallah NG: Ultrasound guided vacuum breast biopsy for microcalcifications in a male. First case report (Article in French). J Med Liban. 2006, 54:161-3.

24. Qu S, Zhang W, Li S, et al.: The vacuum-assisted breast biopsy system is an effective strategy for the treatment of gynecomastia. Aesthetic Plast Surg (Epub ahead of print). 2020, 10.1007/s00266-020-01931-8

25. Whitworth P, Hogan A, Ferko N, et al.: Reduced hospital costs for ultrasound-guided vacuum-assisted excision compared with open surgery in patients with benign breast masses and high-risk lesions. J Breast Imaging. 2020, 2:452-61. 10.1093/jbi/wbaa055 